\title{
Pola Variasi Reguler Medan Magnet Bumi Di Tondano
}

\author{
Teguh Prasetyoa,b* Adey Tanaumaa, As'aria \\ aJurusan Fisika, FMIPA, Unsrat, Manado \\ bBadan Meteorologi Klimatologi dan Geofisika
}

\begin{tabular}{|c|c|}
\hline KATA KUNCI & A B S T R A K \\
\hline $\begin{array}{l}\text { Quiet days } \\
\text { Variasi reguler }\end{array}$ & $\begin{array}{l}\text { Data variasi medan magnet bumi komponen horisontal diambil dari } \\
\text { komputer akuisisi yang merekam data secara real time. Dibuat grafik data } \\
\text { magnet bumi komponen horisontal versus waktu per hari. Dipilih grafik } \\
\text { quite days dan dibandingkan dengan quiet days di Lerwick (Inggris). } \\
\text { Dihitung nilai rata-rata dari Quiet days yang sama perbulan untuk } \\
\text { dijadikan pola variasi reguler bulanan, sehingga dalam satu tahun dapat } \\
\text { dibuat dua belas pola variasi reguler medan magnet bumi. Hasilnya } \\
\text { menunjukkan bahwa variasi reguler medan magnet bumi polanya teratur, } \\
\text { nilai variasi tertinggi berkisar } 39308,3 \mathrm{nT}-39409,5 \mathrm{nT} \text { pada kisaran } \\
\text { waktu 02:39 - 03:38 Universal Time. Pola variasi reguler medan magnet } \\
\text { bumi digunakan sebagai acuan untuk menganalisis variasi harian medan } \\
\text { magnet bumi. Pada tahun } 2011 \text { tercatat badai besar geomagnet } \\
\text { sebanyak } 11 \text { kali yang nilai variasinya berkisar } 71-20 \mathrm{nT} \text { dengan nilai K } \\
\text { indeks sama dengan lima. }\end{array}$ \\
\hline
\end{tabular}

\begin{tabular}{l}
$\overline{\text { K E Y W O R D S }}$ \\
\hline Quiet days \\
Regular variation
\end{tabular}

AVAILABLE ONLINE

25 Februari 2014

\section{A B S T R A C T}

Data variation of the horizontal component of the earth's magnetic field was taken from the acquisition computer which records data in real time. Graphs describing the horizontal component data versus time were created daily. Graphs of quiet days were selected and compared with quiet days in Lerwick (England). Average value the same of quiet days were calculated in order to create monthly regular variation pattern, so that in one year there were twelve regular variation patterns of the earth 's magnetic field created. The results showed that the regular variations of the earth 's magnetic field is on a regular pattern, the value of the highest variation ranged 39308.3 $\mathrm{nT}$ - $39409.5 \mathrm{nT}$ at around 2:39 to 3:38 Universal Time. Regular variation patterns of the earth 's magnetic field were used as references for analyzing the daily variation of the earth 's magnetic field. In 2011, the large geomagnetic storms were recorded 11 times, the value of the variation range $71-20 \mathrm{nT}$ with the $\mathrm{K}$ index value equal to five.

\footnotetext{
1. Pendahuluan

Bumi adalah magnet besar, menurut teori dinamo medan magnet bumi berasal dari arus listrik yang dihasilkan oleh efek kopel konveksi dan rotasi inti luar bumi yang cair dari besi dan nikel (Untung, 2001). Kemagnetan besi dan nikel dihasilkan dari arus listrik yang berasal dari aliran elektron mengelilingi inti besi dan nikel serta spin elektron
}

yang tidak berpasangan. Garis-garis gaya medan magnet bumi merupakan perisai magnetik yang sangat kuat sehingga mampu menahan ledakan dari matahari yang berupa flare dan CME (Coronal Mass Ejection) yang sangat dasyat (Sulistiani, 2012).

Medan magnet bumi yang sumbernya berasal dari dalam inti bumi dan kerak bumi relatif tetap sedangkan yang dari luar bumi yang selalu 
mengalami perubahan atau variasi setiap saat, baik variasi reguler maupun variasi tidak reguler (Kamide dan Berekke, 1975).

Variasi reguler medan magnet bumi adalah perubahan nilai medan magnet bumi yang disebabkan rotasi bumi sedangkan variasi tidak reguler yang dikenal dengan gangguan medan magnet bumi disebabkan antara lain oleh aktivitas matahari, gempa bumi, gunung meletus dan aktivitas manusia. Jadi untuk menganalisis gangguan medan magnet bumi harus dibuat dulu pola variasi regulernya.

Di Pos Pengamatan Medan Magnet Bumi Tondano Stasiun Geofisika Manado belum pernah dilakukan penelitian tentang pola variasi reguler medan magnet bumi, sehingga dalam menganalisis gangguan medan magnet bumi mengalami kendala.

\section{Metode}

\subsection{Data}

Pengolahan data dilakukan terhadap data medan magnet bumi komponen horisontal $(H)$ yang direkam oleh sensor variometer secara real time. Data real time komponen $\mathrm{H}$ dikoreksi dengan data pengamatan absolut. Persamaan koreksinya :

$$
H_{b l}=H_{a b s}-\mathrm{d} H \text {... }
$$

Keterangan :

$H_{a b s}=$ Nilai medan magnet bumi komponen horisontal pengamatan absolut (nT).

$H_{b l}=$ Nilai baseline medan magnet bumi komponen horisontal (nT).

$d H \quad=$ Perubahan medan magnet komponen $H$.

\subsection{Metode Pengolahan Data}

Pola variasi reguler dibuat berdasarkan persamaan Amory (1983):

$$
\Delta B=S_{R}+D \text {. }
$$

di mana :

$\Delta B=$ Perubahan medan magnet bumi ( $\mathrm{nT}$ )

$S_{R}=$ Variasi reguler medan magnet bumi harian (nT)

$D=$ Gangguan medan magnet (nT).

Dengan asumsi $\Delta B=d H$ (data pengamatan perubahan medan magnet bumi komponen horisontal), dan $D=0$ ( tidak ada gangguan medan magnet bumi) maka variasi reguler $S_{R}$ dapat dihitung.

Langkah - langkah membuat Pola Variasi Reguler :

a. Data medan magnet bumi komponen $H$ tahun 2011 diambil dari Pos Pengamatan Medan Magnet Bumi Tondano yang tersimpan di komputer akuisisi.

b. Dari data komponen $H$ harian dibuat grafik komponen $H$ (nilai $H$ ) terhadap waktu di komputer pengolahan data, menggunakan Microsoft Excel .

c. Dipilih grafik yang normal (Quiet days), kemudian dibandingkan dengan quiet days dari BGS (British Geological Survey). d. Dari beberapa grafik yang normal kemudian dibuat rata-ratanya, maka akan didapatkan grafik pola variasi reguler $\left(S_{q}\right)$ per bulan.

$$
\mathrm{S}_{q}=\frac{\sum_{i=1}^{n} S_{R}}{\mathrm{n}}
$$

Keterangan :

$$
\begin{aligned}
S q= & \text { Pola variasi reguler medan magnet bumi } \\
& \text { yaitu rata-rata bulanan dari } S_{R} . \\
n= & \text { Banyaknya } S_{R} \text { dalam satu bulan. }
\end{aligned}
$$

\subsection{Metode Analisis}

Analisis nilai $K$ indeks data variasi harian medan magnet bumi dilakukan dengan cara membandingkan data variasi harian dengan pola variasi reguler medan magnet bumi bulanan. Langkah selanjutnya adalah :

1. Menghitung selisih nilai data variasi harian $\left(H_{i}\right)$ dengan nilai pola variasi reguler medan magnet bumi bulanan $(\mathrm{Sq})$,

$\Delta H=H_{i}-S q$ tiap menit dalam satu hari.

2. Menghitung nilai penyimpangan $\Delta H_{\max }$ tiap 3 jam.

3. Menghitung nilai penyimpangan $\Delta H_{\min }$ tiap 3 jam.

4. Menghitung selisih nilai perubahan medan magnet komponen horiontal

$$
\Delta H_{3 j a m}=\left|\Delta H_{\max }-\Delta H_{\min }\right| \text {. }
$$

5. Konversi $\Delta H_{3 j a m}$ ke tabel $\mathrm{K}$ indeks magnet bumi.

6. Nilai $\mathrm{K}$ menunjukkan tingkat gangguan medan magnet.

\section{Hasil dan Pembahasan}

\subsection{Hasil Penelitian}

Pengamatan dilakukan di Pos Pengamatan Tondano, Stasiun Geofisika Manado dengan menggunakan Fluxgate variometer. Hasil pengamatan berupa komponen medan magnet horisontal $(H)$,

Pada tahun 2011 terdapat 365 grafik komponen $H$ versus waktu. Pada kelompok data bulanan dipilih grafik yang kurvanya halus, yang menunjukkan bahwa hari itu adalah quiet day (hari tenang) yaitu selama hari itu tidak terjadi gangguan lokal dan kondisi ionosfer tenang dengan indeks aktivitas magnet ( $\mathrm{K}$ indeks) bernilai $\mathrm{O}$ atau 1 pada Tabel 1.

Tabel 1. Konversi kondisi ionosfer, $\mathrm{K}$ indeks dan fluktuasi H (Anonymous, 2012)

\begin{tabular}{|c|c|c|}
\hline Keadaan lonisfer & K-indeks & Fluktuasi H $(\mathrm{nT})$ \\
\hline Tenang & $0-1$ & $0-10$ \\
\hline Tidak tenang & 2 & $11-20$ \\
\hline Aktif & 3 & $21-40$ \\
\hline Badai kecil & 4 & $41-70$ \\
\hline Badai besar & 5 & $71-120$ \\
\hline Badai sangat kuat & 6 & $>121$ \\
\hline
\end{tabular}

Kemudian grafik yang polanya halus dalam tiap bulan dibandingkan dengan perhitungan secara otomatis nilai $\mathrm{K}$ indeks di Lerwick (BGS, 2011). 
Perbandingan jumlah hari tenang antara British Geological Survey dan data pengamatan tersaji dalam Tabel 2.

Tabel 2. Konversi kondisi ionosfer, $\mathrm{K}$ indeks dan fluktuasi $\mathrm{H}$ (Anonymous, 2012)

\begin{tabular}{|l|l|l|l|l|}
\hline No & \multicolumn{1}{|c|}{ Bulan } & \multicolumn{1}{|c|}{$\begin{array}{c}\text { BGS } \\
\text { Tanggal }\end{array}$} & $\begin{array}{c}\text { Data } \\
\text { Pengamatan } \\
\text { Tanggal }\end{array}$ & $\begin{array}{c}\text { Jumlah } \\
\text { Hari } \\
\text { Tenang } \\
\text { yang } \\
\text { Sama }\end{array}$ \\
\hline 1 & Januari & $2,21,22,23,27$ & $21,22,23,27$ & 4 \\
\hline 2 & Februari & $3,9,13,22,38$ & 9,22 & 2 \\
\hline 3 & Maret & $15,16,26$ & $15,16,26$ & 3 \\
\hline 4 & April & 26,27 & 26,27 & 2 \\
\hline 5 & Mei & $8,12,13,14,21,25$ & 8,12 & 2 \\
\hline 6 & Juni & $3,19,27,29$ & 29 & 1 \\
\hline 7 & Juli & $16,27,28$ & 27,28 & 2 \\
\hline 8 & Agustus & $3,13,18,19,21,30,31$ & $18,19,30$ & 3 \\
\hline 9 & September & $1,2,8,14,16,19,23,24$ & $8,16,23,24$ & 4 \\
\hline 10 & Oktober & $7,10,13,14,18,22,23,28,29$ & $13,28,29$ & 3 \\
\hline 11 & November & $4,6,7,9,11,13,14,18,19,20,27$ & 14,19 & 2 \\
\hline 12 & Desember & $6,7,15,16,17,18,23,24,25,26,27$ & $15,16,26,27$ & 4 \\
\hline
\end{tabular}

Pola variasi reguler dibuat tiap bulan dengan cara membuat grafik nilai rata-rata komponen $H(\mathrm{nT})$ dari jumlah hari tenang tiap bulan versus waktu dalam menit yang sama. Dihasilkan 12 (dua belas) pola variasi reguler bulanan. Gambar 1 dan 2 adalah gambar pola variasi reguler medan magnet bumi di Tondano bulan Januari sampai bulan Desember.

\subsection{Pembahasan}

Pola variasi reguler bulanan pada Gambar 1 dan 2 memberikan informasi bahwa perubahan medan magnet bumi secara umum polanya teratur, kenaikan nilai perubahan medan magnet bumi terjadi pada permukaan bumi yang menghadap matahari karena pada saat itu terjadi ionisasi gas netral seperti gas oksigen dan nitrogen oleh sinar ultra violet, akibatnya mengalir arus elektojet dari barat ke timur. Sesuai dengan hukum Faraday aliaran arus ini menimbulkan medan magnet induksi. Secara numerik nilai pola variasi reguler medan magnet bumi yang dihitung di Tondano ditunjukkan dalam Tabel 3. Tabel 3 menunjukkan karakteristik pola variasi reguler bulanan seperti tertera dalam Tabel 4.

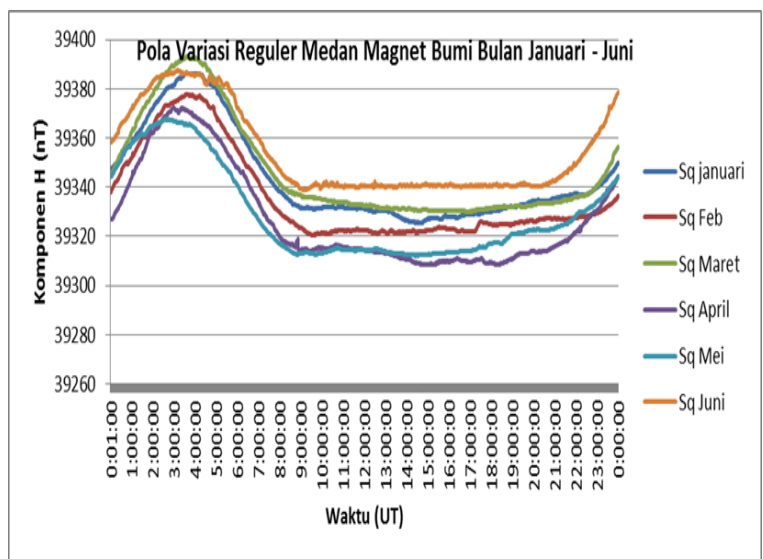

Gambar 1. Pola variasi reguler medan magnet bumi bulan Januari-Juni 2011.

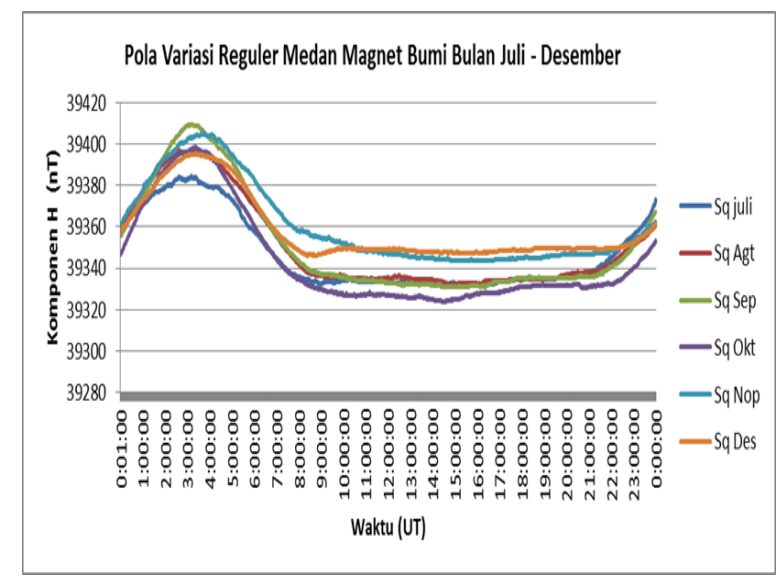

Gambar 2. Pola variasi reguler medan magnet bumi bulan Juli-Desember 2011.

Pola variasi reguler medan magnet bumi berguna untuk menganalisis gangguan medan magnet bumi yang bumi berfungsi sebagai pengurang, berdasarkan persamaan Amory pada Persamaan 2 dan 3. Hasil analisis harian dalam tahun 2011 sebagaimana tertera dalam Tabel 5 .

Tabel 3. Nilai pola variasi reguler bulanan

\begin{tabular}{|c|c|c|c|c|c|c|}
\hline Bulan & $\begin{array}{c}\text { Maksimum } \\
\mathrm{nT}\end{array}$ & $\begin{array}{c}\text { Jam } \\
\text { UT }\end{array}$ & $\begin{array}{c}\text { Minimum } \\
\mathrm{nT}\end{array}$ & $\begin{array}{c}\text { Jam } \\
\text { UT }\end{array}$ & $\begin{array}{c}\text { Maks-Min } \\
\mathrm{nT}\end{array}$ & $\begin{array}{c}\text { Rata-rata } \\
\mathrm{nT}\end{array}$ \\
\hline Januari & 39386,6 & $3: 35: 00$ & 39325,3 & $14: 38: 00$ & 61,4 & 39343,9 \\
\hline Februari & 39377,7 & $3: 34: 00$ & 39320,5 & $9: 32: 00$ & 57,2 & 39336,0 \\
\hline Maret & 39393,0 & $3: 35: 00$ & 39329,8 & $14: 51: 00$ & 63,2 & 39346,5 \\
\hline April & 39372,4 & $2: 58: 00$ & 39308,3 & $14: 49: 00$ & 64,1 & 39327,4 \\
\hline Mei & 39367,9 & $2: 42: 00$ & 39312,3 & $14: 23: 00$ & 55,6 & 39329,2 \\
\hline Juni & 39387,4 & $3: 10: 00$ & 39338,8 & $9: 11: 00$ & 48,6 & 39354,1 \\
\hline Juli & 39384,5 & $3: 11: 00$ & 39331,4 & $15: 15: 00$ & 53,1 & 39347,1 \\
\hline Agustus & 39396,9 & $2: 39: 00$ & 39332,1 & $14: 59: 00$ & 64,8 & 39350,7 \\
\hline September & 39409,5 & $3: 13: 00$ & 39330,8 & $14: 52: 00$ & 78,7 & 39351,5 \\
\hline Oktober & 39398,3 & $3: 23: 00$ & 39324,0 & $14: 28: 00$ & 74,3 & 39344,1 \\
\hline November & 39405,0 & $3: 38: 00$ & 39343,4 & $16: 06: 00$ & 61,6 & 39360,6 \\
\hline Desember & 39395,1 & $3: 23: 00$ & 39346,2 & $8: 43: 00$ & 48,9 & 39358,6 \\
\hline
\end{tabular}


Tabel 4. Karakteristik pola variasi reguler medan magnet bumi di Tondano.

\begin{tabular}{|l|l|c|c|l|}
\hline No & Besaran & Nilai & Satuan & Keterangan \\
\hline 1 & $\begin{array}{l}\text { Maksimum } \\
\text { absolut }\end{array}$ & 39409,5 & $\mathrm{nT}$ & $\begin{array}{l}\text { Bulan } \\
\text { September }\end{array}$ \\
\hline 2 & $\begin{array}{l}\text { Minimum } \\
\text { absolut }\end{array}$ & 39308,3 & $\mathrm{nT}$ & Bulan April \\
\hline 3 & $\begin{array}{l}\text { Rata-rata } \\
\text { tahunan }\end{array}$ & 39345,8 & $\mathrm{nT}$ & $\begin{array}{l}\text { Tahun } \\
2011\end{array}$ \\
\hline 4 & $\begin{array}{l}\text { Amplitudo } \\
\text { maksimum }\end{array}$ & 78,7 & $\mathrm{nT}$ & $\begin{array}{l}\text { Bulan } \\
\text { September }\end{array}$ \\
\hline 5 & $\begin{array}{l}\text { Amplitudo } \\
\text { minimum }\end{array}$ & 48,6 & $\mathrm{nT}$ & Bulan Juni \\
\hline 6 & $\begin{array}{l}\text { Amplitudo } \\
\text { rata-rata }\end{array}$ & 61,0 & $\mathrm{nT}$ & $\begin{array}{l}\text { Tahun } \\
2011\end{array}$ \\
\hline 7 & $\begin{array}{l}\text { Selang waktu } \\
\text { maksimum }\end{array}$ & $\begin{array}{c}02: 39- \\
03: 38\end{array}$ & UT & $\begin{array}{l}\text { Ionisasi } \\
\text { maksimum }\end{array}$ \\
\hline 8 & $\begin{array}{l}\text { Selang waktu } \\
\text { minimum }\end{array}$ & $\begin{array}{c}08: 43- \\
16: 51\end{array}$ & UT & $\begin{array}{l}\text { Ionisasi } \\
\text { minimum }\end{array}$ \\
\hline
\end{tabular}

Tabel 5. Hasil analisis nilai $\mathrm{K}$ indeks maksimum medan bumi tahun 2011.

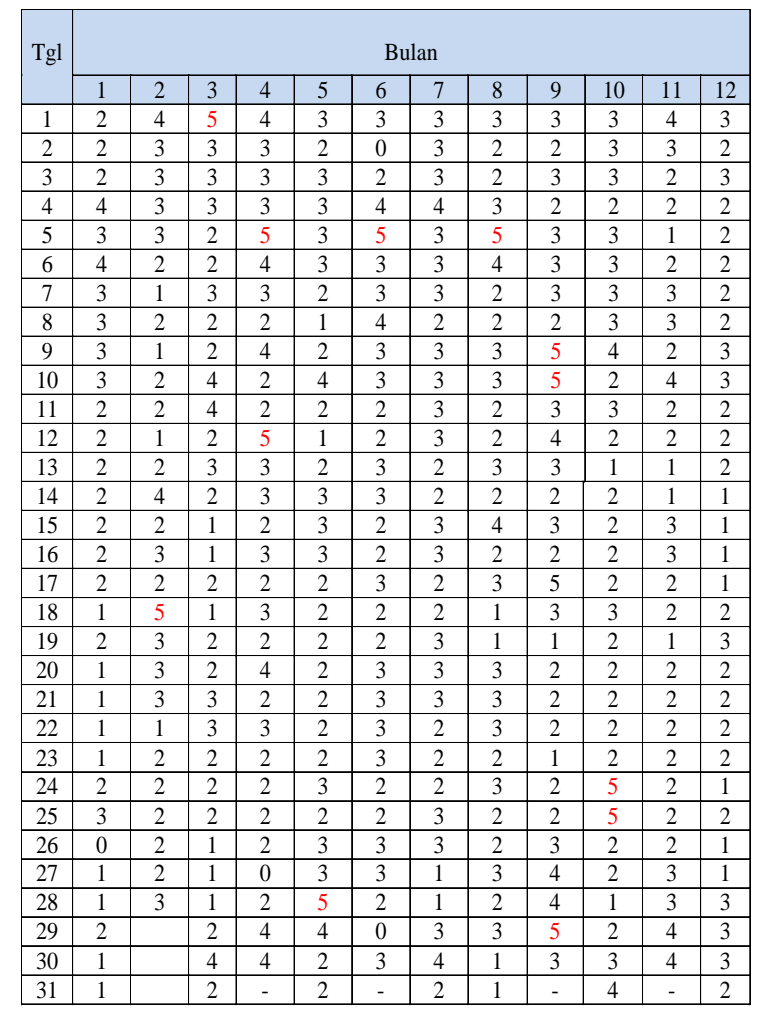

Tabel 5 menunjukkan bahwa nilai $\mathrm{K}$ indeks terbesar adalah 5 (badai besar) terjadi 11 kali selama tahun 2011 yaitu pada tanggal : 18 Februari, 1 Maret, 5 April, 12 April, 28 Mei, 5 Juni, 5 Agustus, 9-10 September, 17 September, 29 September, 24-25 Oktober. Kemudian kejadian badai menurut hasil penelitian dibandingkan dengan nilai $K$ indeks magnet bumi hasil perhitungan otomatis dari Lerwick (BGS) yang berkoordinat 600 09' $20^{\prime \prime} \mathrm{LU}$ dan $1^{\circ}$ 08' 40"BB, tertera pada Tabel 6.
Tabel 6. Perbandingan nilai $K$ indeks hasil Penelitian dengan nilai $\mathrm{K}$ indeks hasil perhitungan otomatis dari Lerwick (BGS).

\begin{tabular}{|c|l|c|l|c|}
\hline \multirow{2}{*}{ Nomor } & \multicolumn{2}{|c|}{ Hasil Penelitian } & \multicolumn{2}{c|}{ Lerwick (BGS) } \\
\cline { 2 - 5 } & \multicolumn{1}{|c|}{ Tanggal } & Nilai K indek mak & \multicolumn{1}{c|}{ Tanggal } & Nilai K indek mak \\
\hline 1 & 18 Februari & 5 & 18 Februari & 3 \\
\hline 2 & 1 Maret & 5 & 1 Maret & 6 \\
\hline 3 & 5 April & 5 & 5 April & 3 \\
\hline 4 & 12 April & 5 & 12 April & 4 \\
\hline 5 & 28 Mei & 5 & 28 Mei & 6 \\
\hline 6 & 5 Juni & 5 & 5 Juni & 7 \\
\hline 7 & 5 Agustus & 5 & 5 Agustus & 8 \\
\hline 8 & 9-10 September & 5 & 9-10 September & 6 \\
\hline 9 & 17 September & 5 & 17 September & 4 \\
\hline 10 & 29 September & 5 & 29 September & 4 \\
\hline 11 & 24-25 Oktober & 5 & 24-25 Oktober & 8 \\
\hline
\end{tabular}

Tanggal 1 Maret, 28 Mei, 5 Juni, 5 Agustus, 910 September dan 24-25 Oktober nilai $\mathrm{K}$ indeks saat terjadi badai magnet di Lerwick lebih besar dari nilai $\mathrm{K}$ indeks di Tondano, hal ini disebabkan aliran partikel berenergi tinggi yang terpancar dari matahari mengenai belahan bumi yang berhadapan dengan matahari dengan arah tegak lurus medan magnet bumi akan dihamburkan oleh magnetosfer sehingga tidak mencapai permukaan bumi. Arah hamburan ke kutub magnet bumi, sehingga garisgaris hamburan semakin rapat ke arah kutub. Hal ini menyebabkan variasi medan magnet ke arah kutub (lintang tinggi) semakin besar. Akibatnya nilai $\mathrm{K}$ indeks magnet bumi di daerah lintang tinggi pada saat terjadi badai lebih besar dari daerah sekitar ekuator termasuk Tondano.

Tanggal 18 Februari, 5 April, 12 April, 17 September dan 29 September nilai $\mathrm{K}$ indeks di Tondano lebih besar dari nilai $\mathrm{K}$ indeks BGS, hal ini diduga karena faktor-faktor lokal yang dapat mempengaruhi variasi medan magnet bumi di sekitar daerah Tondano. Faktor-faktor lokal tersebut adalah strokes, flashes dan awan yang mengandung mutan listrik di sekitar daerah Tondano. Strokes adalah aktifitas kelistrikan yang teridentifikasi sebagai kejadian petir sedangkan flashes adalah aktifitas kelistrikan yang merupakan/terdiri dari beberapa strokes, ditandai dengan adanya kilatan petir (BMKG, 2011).

Gambar 3 sampai 7 memperlihatkan keadaan strokes dan flashes di sekitar daerah Tondano tanggal 18 Februari, 5 April, 12 April, 17 September dan 29 September yang terdeteksi di Stasiun Geofisika Manado.

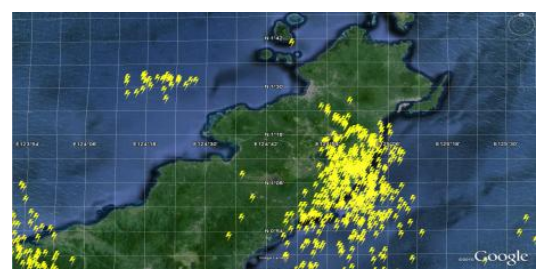

Gambar 3. Flashes tanggal 18 Februari 2011. 


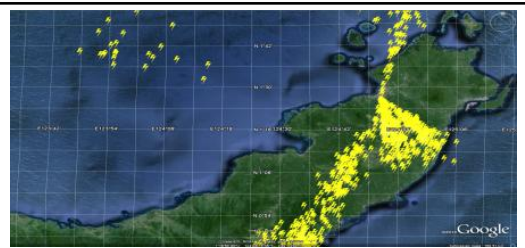

Gambar 4. Flashes tanggal 5 April 2011

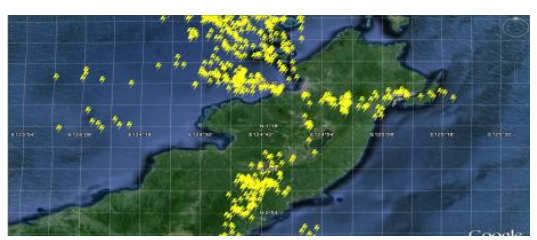

Gambar 5. Flashes tanggal 12 April 2011

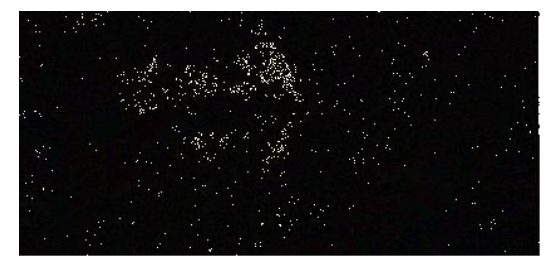

Gambar 6. Flashes tanggal 17 September 2011

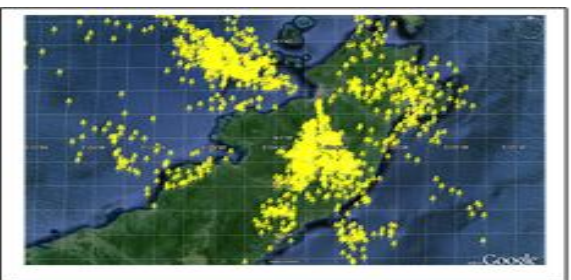

Gambar 7. Flashes tanggal 29 September 2011

Aktivitas kelistrikan yang yang teramati pada data synop M.E.48 di Tondano tanggal 18 Februari, 5 April, 12 April, 17 September dan 29 September 2011 terdiri dari: guntur, kilat dan awan bermuatan listrik (awan Cb) tertera pada Tabel 7. Data synop M.E.48 adalah data pengamatan unsur-unsur cuaca yang diamati tiap jam . Unsur-unsur cuaca tersebut adalah jarak pandang, hujan, angin, udara, penyinaran matahari, penguapan air, perawanan, kilat dan guntur yang ditulis dengan format synop yang dikirim tiap 3 jam ke Organisasi Meteorologi Dunia (BMKG, 2011).

Data guntur, kilat dan awan cumulonimbus (awan $\mathrm{Cb}$ ) yang tertera dalam Tabel 7 meningkatkan aktivitas kelistrikan di sekitar daerah Tondano sehingga variasi medan magnetnya semakin besar, akibatnya $\mathrm{K}$ indeks medan magnet bumi di Tondano lebih besar dari $\mathrm{K}$ indeks medan magnet di Lerwick, Inggris.

Tabel 7. Aktivitas kelistrikan.

\begin{tabular}{|l|l|l|c|c|c|}
\hline \multirow{2}{*}{ Tanggal } & Jam & \multicolumn{4}{|c|}{ Aktivitas kelistrikan } \\
\cline { 3 - 7 } & (UT) & Guntur & Kilat & Awan Cb & Hujan \\
\hline \multirow{5}{*}{ 5 April } & 10 & $\sqrt{ }$ & $\sqrt{ }$ & $\sqrt{ }$ & \\
\cline { 2 - 7 } & 11 & $\sqrt{ }$ & $\sqrt{ }$ & $\sqrt{ }$ & \\
\cline { 2 - 7 } & 11 & & $\sqrt{ }$ & $\sqrt{ }$ & \\
\cline { 2 - 7 } & 12 & & $\sqrt{ }$ & $\sqrt{ }$ & \\
\cline { 2 - 7 } & 13 & & $\sqrt{ }$ & $\sqrt{ }$ & \\
\cline { 2 - 7 } & 18 & & $\sqrt{ }$ & $\sqrt{ }$ & \\
\cline { 2 - 7 } & 19 & & $\sqrt{ }$ & $\sqrt{ }$ & \\
\cline { 2 - 7 } & 20 & & $\sqrt{ }$ & $\sqrt{ }$ & \\
\hline
\end{tabular}

Tabel 7. (sambungan ...)
\begin{tabular}{|c|l|c|c|c|c|}
\hline \multirow{2}{*}{ Tanggal } & Jam & \multicolumn{4}{|c|}{ Aktivitas kelistrikan } \\
\hline & (UT) & Guntur & Kilat & Awan Cb & Hujan \\
\hline 12 April & 4 & $\sqrt{ }$ & $\sqrt{ }$ & $\sqrt{ }$ & $\sqrt{ }$ \\
\hline & 5 & $\sqrt{ }$ & $\sqrt{ }$ & $\sqrt{ }$ & $\sqrt{ }$ \\
\hline \multirow{5}{*}{17 September } & 4 & $\sqrt{ }$ & $\sqrt{ }$ & $\sqrt{ }$ & \\
\hline & 5 & $\sqrt{ }$ & $\sqrt{ }$ & $\sqrt{ }$ & \\
\hline & 6 & $\sqrt{ }$ & $\sqrt{ }$ & $\sqrt{ }$ & \\
\cline { 2 - 7 } & 7 & $\sqrt{ }$ & $\sqrt{ }$ & $\sqrt{ }$ & \\
\hline & 8 & $\sqrt{ }$ & $\sqrt{ }$ & $\sqrt{ }$ & \\
\hline & 9 & $\sqrt{ }$ & $\sqrt{ }$ & $\sqrt{ }$ & \\
\hline & 10 & $\sqrt{ }$ & $\sqrt{ }$ & $\sqrt{ }$ & \\
\hline & 11 & $\sqrt{ }$ & $\sqrt{ }$ & $\sqrt{ }$ & \\
\hline & 12 & $\sqrt{ }$ & $\sqrt{ }$ & $\sqrt{ }$ & \\
\hline \multirow{5}{*}{29 September } & 4 & $\sqrt{ }$ & $\sqrt{ }$ & $\sqrt{ }$ & $\sqrt{ }$ \\
\hline & 5 & $\sqrt{ }$ & $\sqrt{ }$ & $\sqrt{ }$ & $\sqrt{ }$ \\
\hline & 6 & $\sqrt{ }$ & $\sqrt{ }$ & $\sqrt{ }$ & $\sqrt{ }$ \\
\hline & 7 & $\sqrt{ }$ & $\sqrt{ }$ & $\sqrt{y y}$ & $\sqrt{ }$ \\
\hline
\end{tabular}

\section{Kesimpulan}

\subsection{Kesimpulan}

1. Variasi reguler medan magnet bumi bulanan di Tondano memiliki pola teratur, nilai variasi tertinggi berkisar 39308,3 nT - 39409,5 nT pada kisaran waktu 02:39 - 03:38 UT.

2. Tahun 2011 nilai $K$ indeks terbesar di Tondano adalah 5 (71-120 nT) yang berarti badai besar dan terjadi sebelas kali.

\subsection{Saran}

Untuk menghitung $\mathrm{K}$ indeks yang lebih teliti, perlu data penelitian yang lebih lama (minimal 10 tahun) dalam membuat pola variasi reguler.

\section{Daftar Pustaka}

Amory dan Mezauder. 1983. Dynamos and Electric Currents in the Sun Earth System and Use of Magnetic Indices. Dalam 2012 Iswi and Magdas School, Bandung 17-26 September 2012.

Anonymous. 2012. Description of propagation indexes. http://www.dxmaps.com/propindex. html. [25 Januari 2012].

BGS. 2011. Results of $\mathrm{K}$ indices query, England.

BMKG. 2011. Pengamatan magnet bumi, Tondano.

Juangsih, M. 2012.Badai Geomagnet. Buletin Cuaca Antariksa. $1: 3$ hal. 5

Kamide dan Brekke, 1975, Earth's Dynamo. Dalam 2012 Iswi and Magdas School, Bandung 17 -26 September 2012.

Sulistiani, S. 2012. Badai Matahari. Buletin Cuaca Antariksa 1:3 hal. 4.

Untung. 2001. Rekaman Badai Magnet di Stasiun Magnet BMKG. http://www.bmkg.go.id/ BMKG_Pusat/Geofisika/Magnet_Bumi/. [23 Januari 2012]. 